\title{
PATTERN OF INJURIES AMONGST ARMED FORCES PERSONNEL RECEIVED DURING MILITARY ACTIVITIES
}

\author{
Khan $\mathrm{NH}^{1}$, Ahmad $\mathrm{M}^{2}$, Rahman $\mathrm{FN}^{3}$, Ali $\mathrm{M}^{4}$, Rahman $\mathrm{MM}^{5}$
}

\begin{abstract}
Introduction: Armed Forces personnel suffer from various patterns of injuries during their military training activities which may lead to considerable mortality \& morbidity. The high incidence of injuries places a substantial burden on the health care delivery system. Successful treatment outcome and modifications can reduce the operational, fiscal, and health impact of these problems.
\end{abstract}

Objective: To find out the types, causes and morbidity pattern of common injuries received by the members of Bangladesh Armed Forces during their military activities.

Methods: This is a descriptive retrospective study carried out to explore the injuries amongst Bangladesh Armed Forces personnel due to military duties. The study population (193) included all injured indoor cases treated in Combined Military Hospital (CMH) Dhaka during the period of January 2009 to December 2009. Data was collected by reviewing the case sheets of patients and analyzed with the help of SPSS Version 11.5.

Results: Numbers of Injured subjects amongst the Army personnel were $132(68.4 \%)$ followed by $34(17.6 \%)$ in Navy and $27(14 \%)$ in Air Force. Among them $82(42.5 \%)$ belonged to fighting group, $50(25.9 \%)$ supporting and $61(31.6 \%)$ service group. Knee injury constituted the highest number of patients i.e. $43(22 \%)$, followed by
$33(17 \%)$ Armand $25(13 \%)$ foot injuries. About one fourth, $53(27.5 \%)$ cases sustained injury in sports ground followed by $50(25.9 \%)$ in operation area and $28(14.5 \%)$ in training ground. Physical training events PT/Drill caused maximum injury $7(3.6 \%)$ followed by crossing $6 \mathrm{ft}$ wall $5(2.6 \%)$, horizontal rope $4(2.1 \%)$. Maximum duration of hospital stay among the cases were $1-2$ weeks in $65(33.7 \%)$ followed by 3-4 weeks in $56(29 \%)$ and $1-3$ months in $41(21.2 \%)$ cases. Eighty two $(42.5 \%)$ injured cases suffered for 3 to 6 months followed by $43(24.4 \%)$ for 6 months to1 year. Out of all cases $72(37.3 \%)$ were recommended for medical category $C, 2(1 \%)$ for category $B, 11(5 \%)$ were Medically Boarded Out (MBO).

Conclusion: The study revealed that musculoskeletal injuries especially in knee, foot, shoulder, forearm, ankle, lower leg and patella are prevalent in armed forces personnel. The high incidence of injuries places a substantial burden on the health care delivery system and leads to many lost training days. Careful study and analysis in this regard definitely will explore new dimension to prevent and combat this preventable health burden.

Key-words: Injury, Military activity, Armed Forces Personnel.

1. Lt Col Nazmul Huda Khan, MBBS, MPH, ADGMS (Store), Dhaka; 2. Lt Col Mushtaq Ahmad, MBBS, DFM, MCPS, Associate Professor \& Head, Dept of Forensic Medicine \& Toxicology, AFMC, Dhaka; 3. Dr Farial Naima Rahman, MBBS, DMU, Lecturer, Dept of Forensic Medicine \& Toxicology, AFMC; 4. Brig Gen Mohammad Ali, MBBS, DPH, M.Phil, Professor \& Head, Dept of Community Medicine, AFMC, Dhaka; 5. Col Md Mahbubur Rahman, MBBS, FCPS, Professor, Dept of Surgery, AFMC, Dhaka. 


\section{Introduction}

Injury is recognized as a leading health problem worldwide among both civil and military personnel. In 2002, some 161,269 people died as the result of injuries. Fatal injuries (n 106,742) were the leading cause of death for those aged between 1 and 45 years $^{1,2}$. In US, there were 743,547 injury-related musculoskeletal conditions in 2006. In the matrix, $82 \%$ of injury related musculoskeletal conditions were classified as inflammation/pain (overuse), followed by joint derangements $(15 \%)$ and stress fractures $(2 \%)$. The knee/lower leg $(22 \%)$, lumbar spine $(20 \%)$, and ankle/foot $(13 \%)$ were leading body region categories ${ }^{3}$. Each year, an estimated 1.5 million people with injuries are discharged from hospitals, representing the 2nd most common discharge diagnosis and 30 million people are treated for injuries in hospital emergency departments, accounting for $30 \%$ of all emergency department visits ${ }^{4}$. Physical training and physical fitness are required to accomplish military missions. The fitness needed to function in an operational unit varies by the type of unit but in general, are higher in combat arms units than in combat support or combat service support units. Bangladesh Armed Forces personnel are involved in physical training or courses, physical efficiency test, various sports and games; UN adapted training, activities in the field like assault bayonet fighting, unarmed combat, organized drill, parade and basic military training. Coordinated, well-planned and multifaceted approaches based on understanding of the factors involved will have a positive impact on reducing the levels of injuries.

\section{Materials and Methods}

This descriptive retrospective study was carried out to explore the injuries amongst the Bangladesh Armed Forces personnel who received indoor treatment from Combined Military Hospital Dhaka, where referred cases of complicated injuries from all over the Armed Forces units are treated. A total of 772 injured cases received indoor treatment in the orthopaedic, surgical, neurosurgery and officers ward of $\mathrm{CMH}$, Dhaka during the period of January 2009 to December 2009. Cases with injuries received during leave at home or due to personal reasons were excluded. The study populations were all serving uniformed personnel, males and females aged between 18 to 54 years Out of
772 cases every 4th case was selected as per the admission serial for the purpose of data collection; thereby a total of 193 cases had been selected as the study subjects. A checklist was prepared to gather information from case sheets of the treated cases. The research instrument consists of four parts. Part-I contains personal information, Part-II contains information regarding the injuries, Part -III regarding the causes of the injuries and Part-IV about the morbidity of the patients. Data was collected in every working day as per the schedule by scrutinizing/ reviewing the case sheets of the patients confirming it from hospital documents. Required checklist filled with data was edited by thorough checking and rechecking at the end of data collection for omissions or error. The data were entered in computer with the help of soft ware SPSS version 11.5. An analysis plan was developed keeping in mind the objectives of the study.

\section{Results}

The mean age of the cases was $31.52 \pm 7.54$ years and range was $18-52$ years. About one third $67(34.7 \%$ ) of the cases were in the age group between $32-38$ years followed by $51(26.4 \%), 42(21.8 \%)$ and $24(12.4 \%)$ in the age groups between 25-31, 18-24 and 39-45 years respectively. Among the cases almost $1 / 3$ rd of the patients were in the rank of Sainik. Non Commissioned Officers (NCOs) composed $72(37 \%)$ and Junior Commissioned Officers (JCOs) 13(6.7\%) of the cases. The remaining cases were Officers among which $17(8.85 \%)$ were Lt/Equivalent, $13(6.7 \%)$ Major; only $4(2.1 \%)$ were Captain and $4(2.1 \%)$ of the rank of $\mathrm{Lt} \mathrm{Col}$ and above(Fig-1).

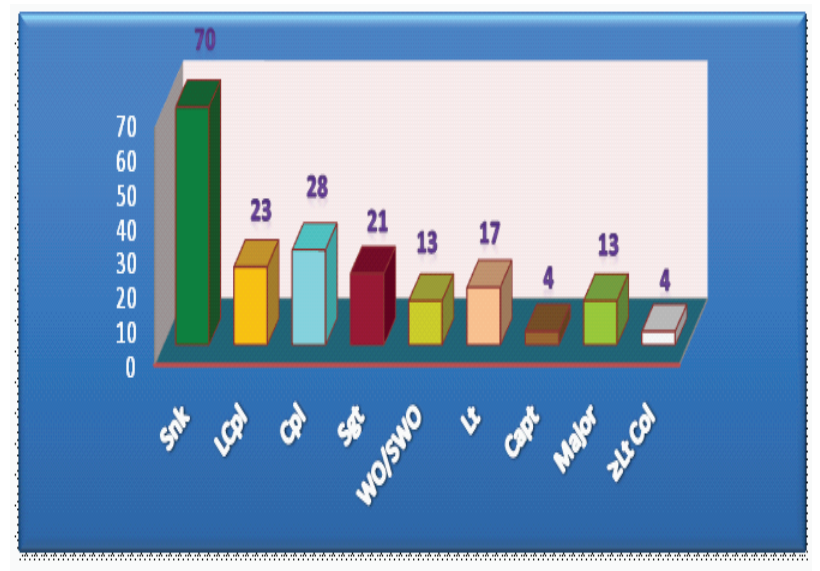

Fig-1: Bar diagram showing the cases according to rank (Equivalent rank of Army, Navy and Air Force) ( $n=193)$. 
As many as $132(68.4 \%)$ were from Army, 34 (17.6\%) from Navy and rest $27(14.0 \%)$ personnel were from the Bangladesh Air force (Fig-2).

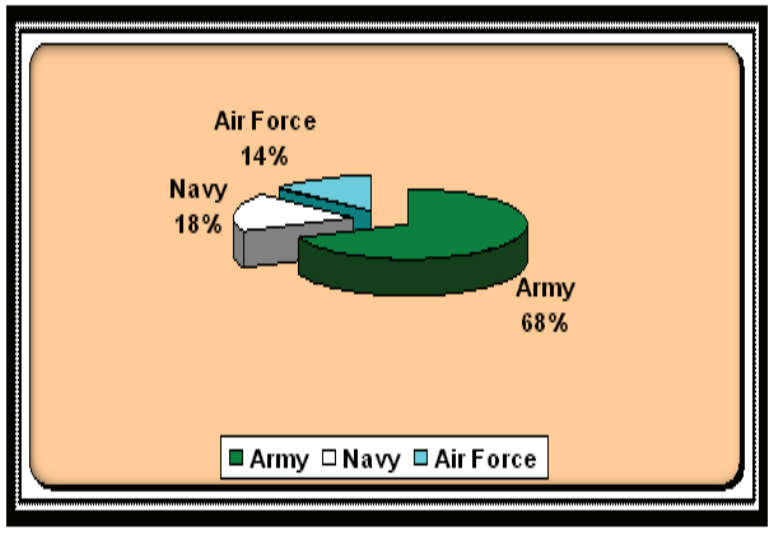

Fig-2: Pie-chart showing the cases according to the Armes Services

Among all the cases $(n=193)$ of the military personnel the number of members of the fighting group were 82 $(42.5 \%)$, supporting group $50(25.9 \%)$ and service group $61(31.6 \%)$ (Table-I).

Table-I: Distribution of the cases according to Arms / Services.

\begin{tabular}{|l|c|c|}
\hline Arms/ Services & Injured persons & Percent \\
\hline Fighting arms & 82 & 42.5 \\
\hline Support arms & 50 & 25.9 \\
\hline Service arms & 61 & 31.6 \\
\hline Total & 193 & 100 \\
\hline
\end{tabular}

Regarding the injuries due to the military activities; games was the main event that has caused $53(27.5 \%)$ case of injuries, followed by operation $40(20.7 \%)$, exercise $10(5.2 \%)$, physical training $28(14.5 \%)$ and about one third $62(32.1 \%)$ cases received injury during administrative duties (Table-II).

Table-II: Distribution of the cases of injury according to the event in military activities $(n=193)$.

\begin{tabular}{|l|c|c|}
\hline Military activity & Injured persons & Percent \\
\hline Games & 53 & 27.5 \\
\hline Operation & 40 & 20.7 \\
\hline Physical training & 28 & 14.5 \\
\hline Exercise & 10 & 5.2 \\
\hline Administrative duties & 62 & 32.1 \\
\hline Total & $\mathbf{1 9 3}$ & $\mathbf{1 0 0}$ \\
\hline
\end{tabular}

In the present study, knee injury constituted the highest number i.e. 43(22.3\%), followed by $33(17.1 \%)$ cases of forearm, wrist and hand injuries, 25(13\%) foot injury, 20(10.4\%) shoulder and arm injury, 13(6.7\%) lower leg injury, $10(13 \%)$ ankle and patella injury each, $8(4.1 \%)$ pelvis and hip injury, $7(3.6 \%)$ spinal injury, $5(2.6 \%)$ head and facial injury, $7(3.7 \%)$ were of injuries in the elbow, neck, Achilles tendon each and $12(6.2 \%)$ other injuries which included bullet injury and injuries in eye, ear and also cut, blunt, burn and scald and dental injuries etc (Fig-3).

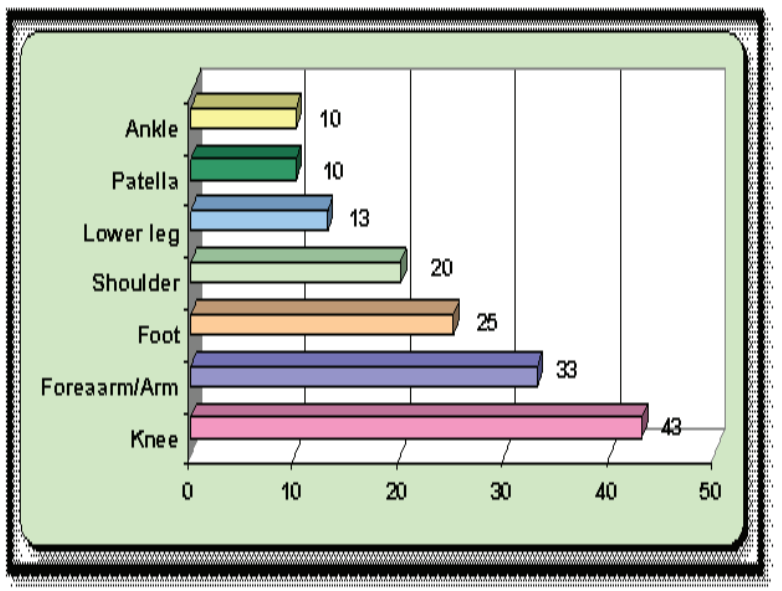

Fig-3: Bar diagram shows the location of injury $(\mathrm{n}=193)$

Out of 28 injuries received during physical training events, PT/drill caused maximum i.e. $7(3.6 \%)$ cases followed by Crossing $6 \mathrm{ft}$ wall $5(2.6 \%)$, Crossing horizontal rope $4(2.1 \%)$, and during assault course 3 $(1.6 \%)$ among others (Fig-4).

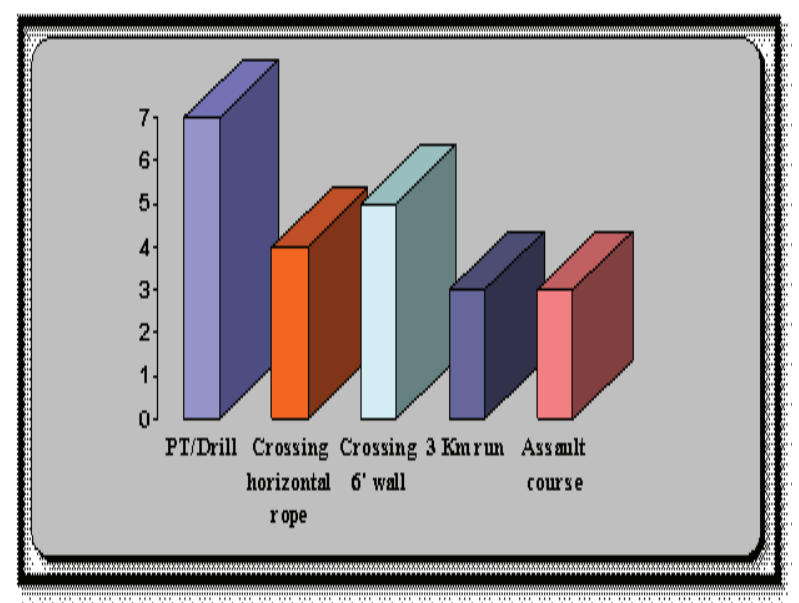

Fig-4: Bar diagram showing the cases of injury according to the events in physical training $(n=193)$. 
It was evident from the study that maximum $24(12.4 \%)$ injuries occurred during playing football followed by volley ball $13(6.7 \%)$ and basket ball 10(5.25\%) (Table-III).

Table-III: Distribution of the cases of injury according to the event of games $(n=193)$.

\begin{tabular}{|l|c|c|}
\hline Events & Injured persons & Percent \\
\hline Foot ball & 24 & 12.4 \\
\hline Volley ball & 13 & 6.7 \\
\hline Basket ball & 10 & 5.2 \\
\hline Swimming & 1 & .5 \\
\hline Athletics & 4 & 2.1 \\
\hline Others & 1 & .5 \\
\hline Total & $\mathbf{5 3}$ & $\mathbf{2 7 . 5}$ \\
\hline
\end{tabular}

Duration of hospital stay for different types of injuries was highest i.e. 65(33.7\%) cases which is for $1-2$ weeks, followed by $56(29 \%)$ for $3-4$ weeks and $41(21.2 \%)$ cases stayed for $>1$ to $<3$ months (Table-IV).

Table-IV: Distribution of the cases according to duration of hospital stay $(n=193)$.

\begin{tabular}{|l|c|c|}
\hline Duration of hospital stay & Frequency & Percent \\
\hline$<7$ Days & 30 & 15.5 \\
\hline 1-2 weeks & 65 & 33.7 \\
\hline 3-4 weeks & 56 & 29 \\
\hline$>1$ month<3 months & 41 & 21.2 \\
\hline 3 to 6 Months & 1 & .5 \\
\hline Total & 193 & 100 \\
\hline
\end{tabular}

Amongst the injured, maximum $82(42.5 \%)$ cases suffered for 3-6 months followed by $47(24.4 \%)$ for 6 months to 1 years and $45(23.3 \%)$ for $7-30$ days. After completion of treatment majority 108 (56.0\%) of the injured personnel returned to medical category A (AYE) followed by $72(37.3 \%)$ medical category $C$ (CEE) and $2(1 \%)$ medical category $B$ $(B E E)$, on the other hand $11(5 \%)$ cases were medically boarded out(MBO).

\section{Discussion}

In this study 132(68.4\%) Army, 34 (17.6\%) Navy and 27 (14.0\%) Air force personnel constituted the sample, among them $82(42.5 \%)$ were from the fighting arms, 50(25.9\%) from supporting arms and $61(31.6 \%)$ cases from the service group. In a study conducted by Hawlader $\mathrm{MAR}^{5}$ at $\mathrm{CMH}$ Dhaka it was found that Army patients constituted $44.56 \%$, followed by Navy $10.56 \%$ and Air force $9.78 \%$ of the sample.

Another study conducted by Zaman $\mathrm{UIC}^{4}$ showed that amongst the injured cases $34 \%$ were from fighting arms, $8 \%$ from supporting arms and $4 \%$ from services arms. Shahidullah $\mathrm{M}^{6}$ found that $70.30 \%$ belonged to fighting group and $29.7 \%$ were from supporting and service group. The findings of the present study are almost similar to the above study results. Regarding rank structure, Shahidullah $\mathrm{M}^{6}$ in his study found that highest number of injury personnel (44.4\%) were Sainik, followed by $13.7 \%$ corporal, Lance corporal $11.4 \%$, sergeant $5.3 \%$ and officer $22.4 \%$ amongst the respondents. This study confers with the present study. Soldiers belonging to the rank of Sainik sustain more injuries than the higher ranking soldiers since they under go more physical activities like; training activities, special training events and sports activities in the unit.

In a study conducted by Hawlader $\mathrm{MAR}^{5}$ on evaluation on trauma management at $\mathrm{CMH}$, Dhaka it was found that musculoskeletal injury was found in $86.22 \%$ of cases, fracture femur in $5.78 \%$, fracture tibia and fibula in $7.89 \%$ of cases, fracture radius and ulna $9.66 \%$, fracture humerus $3.66 \%$, fracture patella $6.11 \%$, fracture clavicle $3.11 \%$, spinal injury $9.11 \%$, head injury $0.11 \%$, dislocation shoulder $4.76 \%$, sprain ankle $7.00 \%$, knee injury $19.77 \%$, muscle and tendon injury in $1.33 \%$ of cases. Hawlader $\mathrm{MAR}^{5}$ also showed that the games was the main events causing injury which occurred in $53(27.5 \%)$ cases, followed by operation/exercise $50(25.9 \%)$ and physical training $28(14.5 \%)$ and during performing daily routine work about one third $62(32.1 \%)$ of the cases received injury. Sports ground was the place where 
maximum injuries of all types occured, such as knee injury in $15(34.9 \%)$ of cases, foot in $8(32 \%)$, fore arm in $6(18.2 \%)$ followed by training ground amounting to knee injury in $10(23.3 \%)$,foot in $5(20 \%)$ and forearm in $8(24.2 \%)$ among others. The findings of our present study are almost similar to the above study results. In another study on basic military training, conducted on musculoskeletal injury among US marine recruits Linenger JM and West $\mathrm{LA}^{7}$ found that training related injuries occurred at a rate of 19.9 injuries per 100 recruits per month. Activities commonly associated with these injuries often involve overtraining, overexertion, repeatative movements and activities, forceful actions, vibratory forces, extreme joint positions, and prolonged static postures etc ${ }^{8-13}$.

In this study it has been found that the incidence of injury $(n=193)$ related to football was maximum in $24(12.4 \%)$ of cases followed by volley ball in $13(6.7 \%)$ and basket ball 10(5.2\%). A study conducted by Rahman $\mathrm{MM}^{14}$ on ankle sprain at $\mathrm{CMH}$, Dhaka showed that the incidence of injury related to football was $40 \%$ and basketball/volleyball $15 \%$ to $17.5 \%$.

Another study carried out by Chan KM et $\mathrm{al}^{15}$ in Thailand found that during sports, knee and the ankle were the commonest sites of injury occuring in $27.27(50.47 \%)$ and $16.78(24.67 \%)$ cases respectively.

In our study out of 28 injuries $(n=193)$ received during physical training events, PT/drill caused maximum amounting to $7(3.6 \%)$ cases followed by Crossing $6 \mathrm{ft}$ wall $5(2.6 \%)$ cases, Crossing horizontal rope $4(2.1 \%)$ and assault course 3 $(1.6 \%)$ cases among others.

Awal $\mathrm{MA}^{16}$ conducted a separate study on knee injury management and showed that in Physical efficiency test (PET) the majority was caused by 9 $\mathrm{ft}$ ditch $(12 \%), 6 \mathrm{ft}$ wall $(8.57 \%)$ and bayonet fighting $(4.29 \%)$. Zaman $\mathrm{UIC}^{17}$ in their study on knee injury in Bangladesh Army found that PET is a prime cause of knee injuries in military personnel (38.09\%). These study outcomes showed similarity with the present study findings. This study also revealed that all those physical trainings had significant relations with the frequencies of the injuries.

This study showed that the average length of hospital stay (ALS) for different types of injuries were highest between 1-2 weeks in 65(33.7\%) cases. Hawlder $\mathrm{MAR}^{5}$ in his study showed that the hospital stay of $42.89 \%$ patients were of $1-2$ weeks, for $24.22 \%$ patients $3-4$ weeks, for $20.22 \%$ patients $5-8$ weeks, for $10 \%$ patients were $9-12$ weeks and for $2.67 \%$ patients more than 12 weeks. According to duration of morbidity; this study showed that, out of 193 injury cases maximum 82(42.5) cases suffered for 3-6 months followed by 6 months to 1 year by $47(24.4 \%)$ cases, $45(23.3 \%)$ cases suffered for $7-30$ days.

Shahidullah $\mathrm{M}^{6}$ showed that $12.7 \%$ cases suffered $>5$ years of disability and more than half in $50.7 \%$ of the cases required time for cure of between 6 months to 1 year and $42.3 \%$ cases suffered for 3-6 months. This study finding shows mild dissimilarity with the present study which may be due to the fact that the previous researcher studied only the knee injury cases.

The injuries and the duration of sufferings revealed in this study statistically are significant $p<0.05$. In this study, after completion of treatment, 108 $(56.0 \%)$ patients had been recommended for medical category A (AYE), followed by $72(37.3 \%)$ cases for medical category $C$ (CEE) and $2(1 \%)$ for medical categories $B$ (BEE).

A study conducted by Rahim $\mathrm{SF}^{18}$ at $\mathrm{CMH}$, Dhaka on knee injury found that $33.33 \%$ were to be regarded as medical category $A$ ( $A Y E$ ), $8 \%$ medical category $B(B E E)$ and $14 \%$ were observed under medical category $C$ (CEE). The results of the two studies are almost similar, mild deviation may be due to the differences in the pattern of injuries in the two studies. 


\section{Conclusion}

The study revealed that musculoskeletal injuries especially in knee, foot, shoulder, forearm, ankle, lower leg and patella are prevalent in Bangladesh Armed Forces personnel who are involved in various kinds of operations, exercises, training, sports and tasks. Study findings also showed high frequency of morbidity in regard. It was evident from the study that a significant number of the injuries are not life threatening-most result only in limited duty for several days. Still the high incidence of injuries places a substantial burden on the health care delivery system and leads to many lost training days. Careful study and analysis in this regard definitely will explore new dimension to combat this preventable health burden.

\section{References}

1. Segui-Gomez M, MacKenzie EJ. Measuring the public health impact of injuries. Epidemiol Rev 2003;25:3-19.

2. Minino $A M$, Anderson RN, Fingerhut LA, Boudreault MA, Warner M. Deaths: injuries, 2002. Natl Vital Stat Report 2006;54(10):1-124.

3. Musculoskeletal Injuries, Description of an Under-Recognized Injury ;Problem Among Military Personnel Keith G. Hauret, MSPH, MPT, Bruce H. Jones, MD, MPH, Steven H. Bullock, DPT, MA, Michelle Canham-Chervak, PhD, MPH, Sara Canada, MPH Am J Prev Med 2010;38(1S):S61-S70.

4. Vyrostek SB, Annest JL, Ryan GW. Surveillance for fatal and nonfatal injuries-United States, 2001. MMWR Surveill Summ 2004;53(7):1-57.

5. Howlader MAR: A study on evaluation of treatment of trauma patients in $\mathrm{CMH}$, Dhaka. BAFMJ Jun; 2004: 49-51.

6. Shahidullah M: Pattern of Knee injury due to physical stress amongst the soldiers attending Combined Military Hospital Dhaka. BAFMJ; 2005:22-25
7. Linenger JM, West LA. Epidemiology soft tissue musculoskeletal injury among US marine recruits undergoing basic military training.[cited 2013 Jan 17] Available from http://www. Pubmed. com.

8. Yassi A. Repetitive strain injuries. Lancet 1997; 349(9056):943-7.

9. Yassi A.Work-related musculoskeletal disorders. Curr Opin Rheumatol 2000;12(2):124 -30.

10. Keyserling WM. Workplace risk factors and occupationalmusculoskeletal disorders, part 1: a review of biomechanicaland psychophysical research on risk factors associated with low-back pain. AlHAJ 2000; 61(1):39 -50.

11. Keyserling WM. Workplace risk factors and occupational musculoskeletal disorders, part 2: a review of biomechanical and psychophysical research on risk factors associated with upper extremity disorders. AlHAJ 2000; 61(2):231- 43.

12. Aptel J, Aublet-Cuvelier A, Cnockaert J. Work-related musculoskeletal disorders of the upper limb. Joint Bone Spine 2002; 69(6):546-55.

13. Waters T, Collins J, Galinsky T, Caruso C. $\mathrm{NIOSH}$ research efforts to prevent musculoskeletal disorders in the healthcare industry. Orthop Nurs 2006; 25(6):380 -9.

14. Rahman MM: A comparative 'study on ankle sprain' at CMH, Ghatail. BAFMJ; June2004: 17-21.

15. Chan KM, Yuan Y, Li CK et al. Five common sport injuries, Thailand Royal Army Medical Journal 1999 july (3): 8-12.

16. Awal MA. Study on knee injury management, CMH, Dhaka. BAFM Journal; Dec 1999: 23-27.

17. Zaman UIC: Knee injuries in Bangladesh Army. A retrospective study of 42 Cases, BAFMJ ;1988; 109-114.

18. Rahim SF: Study on evaluation ACL injury. BAFMJ; June 1997: 59-63. 